\title{
School Libraries as Foundation for World Class Learning: Experiences of an Indian Librarian
}

\author{
Rashmi T Kumbar \\ Librarian \\ Zydus School for Excellence \\ Ahmedabad 380051 \\ Gujarat, India
}

\begin{abstract}
The combination of study of Information and knowledge leading to wisdom; intellectual expression and scholarly appreciation leading to culture is the very process of learning. When this study is considered of high standard throughout the world, it becomes World Class Learning. Schools are the educational institutions wherein children are guided and trained to be disciplined and enlightened individuals. This responsibility is the onus of educators and greatly influenced by the facilities provided at school. The role of educators is highly regarded and recognized but equally important is the impact of the facilities provided in the schools. The most distinct facility is the library or the resource centre. We as information professionals agree that "Libraries Change Lives" which is a universal truth, for the kind of reference resources and the scholarly works they contain. What is the outcome if the resources are highly valued, are in great condition, well organized, etc. but there are no takers for these resources or the users lack the skills to use the resources? Some of the reasons for this short coming may be due to the absence of proper initiatives, promotion of resources and the services by the librarians. This paper attempts at combining the librarianship skills and literacy skills, resulting in the emergence of practical techniques and to how to apply this knowledge for promotion of the resources available and the services offered. Some tried and tested successful strategies namely Structured Library Periods (SLP), Adopt a Book Project (ABP), Five Best Friends in the Library (D.E.A.T.Y.), Focus Group Discussions (FGD), Application of Multiple Intelligence (MI) Theory for the effective use of library resources by K-2 Students, Use of Open Access(OA) Resources in ZSE RC experimented at the author's school are presented. These practices are simple, innovative and create a positive impact on the student. They also increase the library's contribution in achieving the school mission and very easily adaptable by the school libraries or librarians of the developing countries. But there is always scope for refining and improving the strategies tried and tested, in the course of time to suite the ever changing landscape of information and technology and more importantly, to satisfy the ever demanding user and his needs.
\end{abstract}

Program Administration, Multiple Literacies

\section{Introduction}

The combination of study of Information and knowledge leading to wisdom; intellectual expression and scholarly appreciation leading to culture is the very process of learning. When this study is considered of high standard throughout the world, it becomes World Class Learning. Today, 'Important goals of global education are to develop student's sense of place in the world and ideas of the roles and responsibilities of world citizenship'[1]. Schools are the educational institutions wherein children are guided and trained to be disciplined and enlightened individuals. This responsibility is the 
onus of educators and greatly influenced by the facilities provided at school. The role of educators is highly regarded and recognized but equally important is the impact of the facilities provided in the schools. The most distinct facility is the library or the resource centre. We as information professionals agree that "Libraries Change Lives" which is a universal truth, for the kind of reference resources and the scholarly works they contain, apart from the services they offer. What is the outcome if the resources are highly valued, are in great condition, well organized, etc. but there are no takers for these resources or the users lack the skills to use the resources? Some of the reasons for this short coming may be due to the absence of proper initiatives, promotion of resources and the services by the librarians.

\section{Role of School Libraries}

According to Dr. Kathleen D Smith, "School library media centers in the $21^{\text {st }}$ century can, and should be, hub for increased student achievement and positive focused school reform". Further she said "One of the most effective and efficient ways to increase student achievement and love of learning is to leverage the power that library media centers can have in this process.'[2]

In light of the above opinion a few important roles [3] of the school library can be

- Reading being considered as a virtue rather than a habit, begins and develops at the school library \& this virtue helps every student to become a responsible human being

- Support and add on to the teaching process as required by the curriculum, as schools today rely on the resources in their libraries to develop creativity and reasoning skills in young students

- Install in students the advantages of self learning and sustain it lifelong and hence school library is considered as the stepping stones to intellectual and academic career of the students

- Introduce Information Literacy and related activities for better usage of the resources

- Act as a gateway to scholarly information and thereby help them create new knowledge

The National Knowledge Commission (NKC) was constituted in 2005 as a high-level advisory body to the Prime Minister of India, with a mandate to guide policy and generate reforms. It has drawn The Library Charter which is common for all types of libraries in India [4]. It recognizes the Library's objectives as

- To disseminate knowledge as widely as possible;

- To serve as a major vehicle to facilitate creation of new knowledge;

- To facilitate optimal use of knowledge by all sectors, such as government, industry, rural sector and civil society;

- To ensure that people from all sectors and all parts of the country have easy access to knowledge relevant to their needs, in their own language. 


\section{School Libraries as Foundation for World Class Learning}

School libraries work on some basic principles which have to be reaffirmed in order to consider school libraries as foundation for world class learning. Some of them are

- The mission should be committed to Life Long Learning and helping students develop essential library and information skills. It should align with the school's mission and play a pivotal role in the realization of its goals and aim.

- Collaboration is the key component of a successful library program. So the library staff and the teachers should join their hands to bring the students and the resources together for excellent academic output.

- Library has to be proactive to the students and teachers information needs and deliver the best possible services to them.

- Developing efficient tools and techniques to help the teachers and students to recognize their information needs, locate, access, evaluate and use the resources to create new knowledge

- The management and the school administration should realize the need for training the library staff to adopt new technological developments and soft skills in order to deliver world class services to develop a world class learning community

For school libraries to become the foundation of world class learning, we need to meet world class standards for developing excellent resource collection, providing essential facilities and offering innovative services. This can be achieved by meeting national standards primarily and then aiming at international standards. This further calls for efforts to focus on continuous learning and sharing with fellow professionals. The realization of the challenges that the profession brings in and the best practices followed to overcome these challenges, and sharing of these best practices will take us a step closer to our mission of world class learning. With available opportunities, the author has tried some innovative practices which are described in this paper for discussion and value addition by colleagues around the world.

\section{Indian Scenario}

India is witnessing a significant progress in the overall education system, which is a joint responsibility of the states and the centre. While access to schools and colleges remains a major issue in many rural areas, efforts are being made to combine creative aspects and personal development of students along with academics in urban schools.

According to the National Knowledge Commission of India's 2007 report "School education has to be a crucial area of focus if the foundation of a knowledge based society is to be built. The National Knowledge Commission has been examining issues relating to school education across the country, with the aim of framing a set of national level recommendations in this area"[5]. 
An overview of the education system is given below for general understanding.

\section{Indian Education System}

There are mainly four phases of school education namely Kindergarten, Primary, Secondary and High School. Kindergarten comprises of three years - nursery, Junior KG and Senior KG, Primary comprises of classes I to IV, Secondary school comprises of classes V to VIII and High School comprises of classes IX to XII. This division varies from state to state and according to different accreditation Boards but the basic schooling lasts for twelve years following the $10+2$ pattern. All schools are affiliated to any one of the following boards:

- The State Government Boards

- The Central Board of Secondary Education (CBSE)

- The Council for Indian School Certificate Examination (CISCE)

- International School Boards (Ex. IB Programme)

Higher education involves graduation in the fields of Arts \& Humanities, Commerce, Pure sciences and Applied Sciences. Professional courses like engineering takes four years to complete while medical course takes five years and graduation in arts and commerce takes three years to complete. This is further followed by Master's Degree and Doctoral studies in the respective subjects from the Universities. Some of the country's institutes like IITs (Indian Institute of Technology), IIMs (Indian Institute of Management), IISC. (Indian Institute of Science), AIIMS (All India Institute of Medical Sciences) and ISB (Indian School of Business) are world class institutions with world class learning facilities and services. The Ministry of Human Resource Development made of Department of Higher Education and Department of School Education and Literacy are responsible for all levels of education in India.

The major challenges for the government are providing compulsory primary education to all and maintaining quality of education, besides striving to reach $100 \%$ literacy in all states of India. Currently the literacy level is around 65\%. Though it is low compared to many developed countries, Indian academic system is much organized and of high quality compared to many developing countries. The whole process of academics involves lot of learning, researching or literature search which brings in the libraries or information centers into focus.

\section{School Libraries in India}

Libraries of CBSE schools, ICSE schools and some state board schools are doing well while many government run schools do not have libraries and if they have one, they do not have access to the books. Dr. S R Ranganathan, the Father of Library Science in India had said in the context of modern education and role of library as "The Library is the heart of the school, from which every activity in the school radiates and by which in all gets irradiated. The library should literally and figuratively be the hub of every 
educational institution and the librarian should be a guide, philosopher and friend of all its inhabitants" [6].

According to the NKC "The role of libraries in providing widespread and inclusive access to knowledge is widely acknowledged. In today's context, libraries have to play two distinct roles - to serve as a local centre of information and knowledge, and be a local gateway to national and global knowledge. In order to achieve this goal, existing libraries must modernize their collection, services and facilities, become more pro-active and collaborate with other institutions, agencies and NGOs in order to develop a communitybased information system" [7].

Some of the issues under consideration of National Knowledge Commission are:

- institutional framework of libraries;

- networking;

- education, training and research;

- modernization and computerization of libraries;

- maintenance of private and personal collections and

- staff requirements to meet changing needs

According to Dr. S R Ranganathan, the primary objective of school library "is to act as a lever by the aid of which, one of the primary functions of the school is discharged. All the class room work should have a slant towards students work in the library and the class room work and school library work influence each other reciprocally"[8].

\section{Challenges}

Just as school libraries all over the world face challenges, Indian school libraries too face hurdles in achieving their mission. Some of them are mentioned below.

- Budget allocated to the library is inadequate

- Non availability of space and furniture in many government school libraries

- Most of the school libraries are managed by a single professional while some may even lack a qualified librarian

- Role of library and librarian in increasing student achievement is neglected

- Lack of provision for application of technology for library operations

- Failure in motivating teachers and parents to participate actively in library activities

In order to overcome some of these challenges there is an urgent need for introducing innovative methods in various areas of the profession. Very few schools have stood up to the challenges and the librarians are trying hard to make the best use of the opportunities that come to them. Zydus School for Excellence is one such school which has given the liberty to try something new to cross the hurdles and reach out to the students. The next section gives an overview of the school and the library. 


\section{Zydus School for Excellence: an overview}

Zydus School for Excellence has been set up under the aegis of Ramanbhai foundation and is supported by one of India's leading healthcare groups, Zydus Cadila. Zydus School for Excellence is a comprehensive school that aims to provide each student, regardless of ability, with the opportunity to develop his or her full potential. It seeks to create an environment for teaching and learning in which each person is esteemed as a unique individual and to build a community within which each is free to grow in relationship to others. The curriculum provides all students with a series of educational experiences that will form the basis for further development. The aim is to provide a supportive learning environment, which values the uniqueness of each student's experiences and abilities.

\section{Resource Centre (Library)}

The library is commonly called as the Resource Centre and it is regarded as the heart of Zydus School of Excellence. Its role is to support and promote educational goals as outlined in the school's mission and curriculum and the Mission is to enable students and teachers to effectively use information and facilitate them to become life long learners. It is the commitment of the management, teachers and the librarian, to make the Resource Centre as a role model for other schools in the city and all over India. In every respect, it should emerge as the best example in shaping a child's overall personality.

The Resource Centre is housed in two different wings - one meant for the students/teachers of junior classes is located near the Pre-Primary section and the other meant for the senior classes is located in the main building. The Resource Centre houses around twelve thousand books, and around seven hundred CD-ROMs. It is open from $7.30 \mathrm{a} . \mathrm{m}$. in the morning to $3.00 \mathrm{p} . \mathrm{m}$. in the afternoon. Books/Magazines/CDROMs are issued for students of classes VIII - X and only books and magazines for students of classes Jr. KG to class VII for a duration of one week. There is the option of renewing the resources for the duration of one more week. Since the library is open for access for parent members also, a lot of interaction takes place and guidance is given to the parents as to how to use the resources for maximum benefit. Taking regular feed back from the parents and teachers on the child's performance in academics, as well as conducting in the society, helps in promoting the usage of the resources and build a strong collection. It is noticed that a successful partnership has been established between the Library staff, parents and children to encourage reading, books and making use of this to perform well in their academics.

\section{Best Practices}


Steven Bell wrote "Observing the best practices of libraries that are creating passionate users who return again and again may help. It must begin by taking the slower, more thoughtful path of studying the work practices of users and understanding a great library user experience from their perspective" [9]. A Best Practice according to the author in the context of the school library can be "a unique, innovative strategy or a tip; a planned, detailed process or a project that helps to promote library collection, services or create a positive impact on the students' personality and increase the library's contribution to the achievement of the mission of the school" [10]. As library professionals, we are all aware how new and interesting ideas/services can motivate a sea change in usage of the resources and attitudes of the users.

This paper attempts at combining the librarianship skills and literacy skills, resulting in the emergence of practical techniques and to how to apply this knowledge for promotion of the resources available and the services offered. Some tried and tested successful strategies at the author's school are

- $\quad$ Structured Library Periods (SLP)

- Adopt a Book Project (ABP)

- Five Best Friends in the Library (D.E.A.T.Y.)

- Focus Group Discussions (FGD)

- Application of Multiple Intelligence (MI) Theory for the effective use of library resources by K-2 Students

- Use of Open Access(OA) Resources in ZSE RC

They have been presented individually below with reference to, the context of the practice, the objectives of the practice, the practice itself, the evidence of success and the resources required to carry out the practice.

\section{Structured Library Periods (SLP)}

Zydus School for Excellence has an excellent print collection of 12,000 books including reference, fiction and non fiction. Except for reference all other books (Age appropriate) are free for issuing. Children are usually conditioned in the Indian context to read story books or novels or magazines for pleasure or entertainment and the concept of reading non fiction like biographies, know-how books, hobbies, sports, etc. is not in vogue. To make best use of the library periods for all classes (twice a week), this concept was started so that the children know that apart from reading story books and novels there is much more to read, understand and use it for their academic purpose.

This practice was introduced with the following objectives. Namely,

- Creating awareness among students about different types of resources available in the Resource Centre.

- Providing compulsory access to these resources in planned and phase wise manner. 
- Helping students to make use of these resources for fulfilling their research requirement for projects and assignments.

Consistent and constant efforts are made by the librarian to structure each library period and method of conducting library periods. Classes IX \& X have one library period while classes' I-VIII get two library periods in a week. So one period is reserved for issue/return of books and the second period is utilized for free browsing, completion of library assignments, doing their academic literature search etc. The librarian identifies different genre of books like fantasies, folktales, science fiction, historical fiction, biographies, mythology, general knowledge books etc. at the start of the academic year. Then systematically each genre of books is allocated for a week's duration, keeping in mind the age of the children, the font size of the words, the physical condition of the books, etc. 5-10 books more than the actual number of children are kept aside to aide in selection of the book by the children. A brief introduction is given about the books that are going to be issued that particular week and why they have been chosen. Then an assignment or report is planned on that particular collection, usually any one particular genre of book is chosen as the assignment topic.

This practice is being experimented since the last five years and some success parameters that have been observed are as mentioned below

- Students learn to use all types of resources at an early age.

- Academic performance of students increases due to their ability to research the lessons and gather information from various sources in the library for projects, assignments, etc.

- General awareness and performance in many non-academic activities (Quiz, debates, elocution, posture presentation, etc) increases as ideas are gathered from various resources available in the library.

- Children have been found to enjoy the process of discovering the knowledge contained in various types of resources on their own.

A basic requirement to implement this practice is a patient, enthusiastic, well read librarian! Also there should be a neat balance between fiction and non fiction books in the collection so that the goal behind the circulation in this pattern will be achieved. Books should be age appropriate and the font size of the words should be right for that particular age group children. Adequate copies of the books or number of titles of the same genre books should be ready for issuing before the start of the week.

\section{Adopt a Book Project (ABP):}

Zydus School for Excellence Resource Centre has around 2500 subject reference books exclusively for teaching. Since ICSE (Indian Certificate of Secondary Education) board recommends lots of project and activity oriented teaching, teachers can make best use of the subject reference resources for their teaching and planning assignments and projects without wasting much time. 
The following objectives were in mind when this practice was introduced. Namely,

- To make optimum use of teacher resources available in the collection.

- To implement the concept of teacher helping teacher to use the resources for better understanding and teaching of the subject.

- To develop presentation skills among teachers and in the process develop new teaching aids.

- Regular evaluation of these resources and their up gradation

The relevant subject reference books for different subjects are identified at the start of the academic year as well as every month and put on display. When the teachers come to the library; they are encouraged to pick the book of their choice from the display. Then the book is issued to the teacher and after a month of reading and preparing, that teacher has to give a presentation as to know how the book was useful for the purpose of teaching, how the same book can be made use of for a level higher or a level lower and how strongly it is recommended to other teachers teaching the same subject.

Some interesting observations were made when this practice was implemented like

- When a co-teacher recommends a particular book, the other teachers are keen to read it than a librarian recommending a book. Chances of the book being used were higher.

- When issued under a special category and a presentation is expected, teachers genuinely read and prepare. It encourages professional reading.

- New techniques/methods/ ideas emerged from the presentations as other teachers keep adding value during the process.

- Each teacher saves a lot of time and energy to locate the relevant resource, read and make use of it.

For carrying out this practice no additional resources were needed. Whatever resources are available at the $\mathrm{RC}$ are utilized for the project. But teachers and librarians have to work in coordination to bring out the best results. Multimedia facility is needed to carry on the presentations for better impact.

Five Best Friends in the Library (D.E.A.T.Y.):

Reference sources form a core of every library collection and usually costlier also. At Zydus School for Excellence Resource Centre, we have many different kinds of dictionaries, multi volume encyclopedias, atlases, yearbooks, almanacs, thesauruses, etc. In order to make best use of these resources which cannot be issued out, the concept of "Five Best Friends in the Library", namely Dictionary, Encyclopedia, Atlas, Thesaurus, Yearbook was developed. They have been referred as best friends because they are always available in the library when one wants them and are the basic reference sources which are reliable and accurate, and most consulted when one wants to write a report or an assignment. 
The main objectives of introducing this practice were

- Making students aware of the reference section and reference sources in the library.

- Teaching them to choose the appropriate and relevant sources to refer to complete their assignments and projects.

- Helping them with the process of research.

- Teaching them the basic writing skills to write reports and assignments

Each class gets two library periods in a week in our school. The first period of the week is usually utilized for issue-return of books. The second period is used for teaching library/information skills to the students and giving them an assignment based on it. Every month one particular reference source is introduced and explained as to how to use it and then a simple assignment based on it is given to check whether the students have learnt to use the resource and capable of using it for their academic purpose After the end of the second term of the academics, a small project is given on chosen topics to the students, which they have to do in the library itself using these resources. Here the library science skills can be used and the students can be taught as to how to identify the key word in a topic, find the meaning and related terms from the dictionary, and then refer the different kinds of encyclopedias to do the literature search. Then they can consult an atlas and a year book to spice up their writing with maps, facts, figures, etc. and then use a thesaurus to write the assignment in their own words. Note taking skills, basic writing skills and editing skills are explained along with teaching them as to how to prepare a bibliography and how to list references, so that the students learn fair use of information and give credit where it is due.

Some success factors observed after introducing this practice were

- Students find it interesting to refer to these resources more often as they believe that they are their friends to help with their academics.

- They learn to understand the process of research in a simple, systematic manner.

- Once they learn to search and refer for smaller topics in the library, without being graded, they gain confidence to take up projects and assignments concerning their academics as they now know the basic search skills.

- Students learn the report/assignment writing skills efficiently after this exercise.

They only resource requirement needed would be workbooks which help in framing assignments based on these reference sources. Also multiple copies of these resources will keep the students focussed and interested while completing their projects.

Focus Group Discussions (FGD): 
According to Brey-Casians, El Paso Public Library Director, "The most important characteristic of the library of the future is its role as place - a destination for many who seeks a social environment in which to learn and grow" [11]. Considering school library as a foundation for world class learning, it is essential that the library should be the place to attempt to involve students by engaging them in meaningful activities which will successfully end up in collecting their thoughts and feelings regarding the collection, facilities and services, apart from those of the school. Since various events like International Children's Book Day, World Book Day, International School Library Day, etc. are celebrated in the library involving students at all levels, they prove to be wonderful opportunities to promote the library's collection and services to them.

The following objectives were to be fulfilled while framing this practice. Namely,

- To understand students expectations from the library and its activities

- To collect students opinions on certain issues concerning the collection, services, facilities of the library

- To improve existing facilities and services of the library and design new services for the students

- To develop techniques and strategies for reaching out to various groups of students through our services

As Focus Group Discussions occur in three phases namely Conceptualization phase, Interview phase and Analysis - Reporting phase, a little preparation is necessary to plan the sequence of things in phase wise manner, with certain modifications since the participants involved here are the students and the library is an intangible service. The conceptualization phase includes determining the purpose like what will be the topic of discussion, how will it benefit the library and its services, determining the specific group of students who will participate and who will be the moderator and facilitator, and developing a plan to carry out the discussion. In the interview phase, questions are developed in a logical sequence but space is provided for unanticipated questions too. Instead of going for a single moderator, a moderator team is usually constituted. The main moderator is either the administrator or a teacher and the facilitator is the librarian who takes notes, handles organizing aspects, preparing the report, etc. Usually the library is the venue for the discussion and the regular library period of the particular student group is utilized for the discussion. The seating arrangement is done in such a way that those students who are not participating can still access the resources and carry on with their reading while their peers are participating in the discussion. Students do volunteer in alerting the participating students about the discussion and handle minor interruptions while the librarian is engaged in the discussion. In the analysis phase, the moderator and the librarian sit together compare their notes, observations, etc and summarize the discussion. Then a detail report is prepared on this basis and put up to the principal and management for discussion and for taking decisions.

This practice has some genuine success factors which are listed below. 
- Students take this opportunity to interact openly with the librarian and put forth their opinions and expectations without hesitation.

- This practice has become a reliable technique to gather data from students regarding various issues concerning collection, facilities and services provided by the library.

- This practice doesn't require elaborate preparation and is much easier to carry out, even it can be used with varied topics and varied student groups.

- Since the librarian is interacting directly with the students, information can also be collected from their body language, gestures, tones, etc. along with their verbal answers

- Since Focus Group Discussions are conducted on the eve of major events, active enthusiastic involvement of the students is noticed.

- Also since the Focus Group Discussions are carried out with the partnership of the school administration, many of the students' suggestions are considered and carried out.

- Most of the discussions end up with the students and library embarking on small projects carried out in the library using the library resources for the benefit of other students, teachers and parents.

- The students come well prepared having read the relevant resources and express their opinions in their own words, which speaks a lot about their confidence and the management is considerate of their opinions and suggestions

Since this practice is carried out in the library, no extra resources are needed except for the librarian's insistence to use the library resources to get information. This practice is an effective value addition to their education process.

Application of Multiple Intelligence Theory for the effective use of library resources by K-2 Students [12]

Dr. Howard Gardner a professor of education and coordinator of project Zero at Harvard University, challenged the traditional notion that intelligence is a single capacity possessed by every individual to a greater or lesser extent. Armed with research evidence, Dr. Gardner presents the idea of existence of a number of intelligences that result in a unique cognitive profile for each individual.

According to this theory human cognitive competence is better described in terms of a set of abilities, talents or mental skills called intelligences. All normal individuals possess each of these skills to some extent; individuals differ in the degree of skill and in the nature of their combination. Dr Gardner is of the view that such a theory has important educational implications including ones for curriculum development. Gardner and his team opine that their leads will have to be revised repeatedly in light of actual classroom experience. Yet they believe there are positive reasons for considering the theory of MI and its implications for education. To start with it is clear that many talents if not intelligences are neglected these days, secondly individuals of such talents are victims of single minded or single focused approach to the mind. Recognizing the plurality of intelligences and the manifold ways in which human individual may exhibit them is an important step. 
This opinion of the theory prompted me to take up this concept and apply it to the evaluation of resources at the primary level. Since school library plays a crucial role in a child's reading development, the librarian becomes the promoter who guides the children and the parents and collaborates with the teachers to take up various activities contained in each and every resource by stimulating these intelligences.

The objectives of this practice are

- To stimulate various faculties of the brain/intelligences using books as the aid.

- To boost the child's confidence level by letting him/her evaluate a book

- To increase student achievement level due to knowledge gain and application, by applying the Multiple Intelligence Theory for evaluating a resource.

- To build a successful partnership between the Library staff, parents and children to encourage reading, books and making use of this to perform well in their academics.

The resources issued are a combination of fiction and nonfiction and most of the books issued are such that they stimulate the seven intelligences in one way or the other. Whatever may be the set of resources that is being issued, the children are taught how to identify and evaluate it for optimum use using multiple intelligence characteristics. Since the library is open for access for parent members also, a lot of interaction takes place and guidance is given to the parents as to how to use the resources for maximum benefit. Taking regular feed back from the parents and teachers on the child's performance in academics as well as conducting in the society helps us in promoting the usage of the resources and build a strong collection. So coming to the sequential flow of the whole exercise, as the academic year begins the first 3-4 library periods are utilized in making the children familiar with the concept of books, library \& reading. Once the children get the hang of it, the issuing process begins. Since the library periods are structured, before the start of each library period, the resources that are going to be issued are introduced to the students. Total freedom is given to choose a book of their choice from the set that has been laid out for issuing. Opinion as to how they liked or why they disliked a certain series or book is carefully taken into consideration. The evaluation begins with the librarian getting involved and chooses one resource from the pile that has been kept ready for issuing. The pre-chosen book is displayed and a series of questions which satisfy various multiple intelligences are asked. The children are then encouraged to use the same method to chose a book which stimulates the various intelligences to take home.

The results of this practice are mentioned below

- Students showed increased interest in coming to the library and were excited about issuing books to take home and go through various books.

- Interestingly both fiction and non-fiction are sought after and therefore are used to the optimum level. 
- Since parents are also encouraged to take membership of the library, most member parents are highly motivated in taking interest in their children's reading habits and are excited with this logical method of evaluating a resource.

- The positive feedback from the faculty regarding involvement in curriculum related research activities gives an idea about the factors as to which resources help or hinder academic development.

- This is one form of Information Literacy practiced at the very grass root level and is cost effective as an attempt is made to promote all the resources that are bought are also made use of.

Resource requirement to implement this practice would be Dr. Howard Gardner's works namely Multiple Intelligences: the theory in practice, Frames of Mind: the theory of Multiple Intelligences, etc need to be in the collection. Picture books, books with larger print are a must for Junior Resource Centre. A prior training or hands-on is imparted to library staff and parents. Consistent and repeated efforts on the part of the librarian to help children evaluate the books are essential and at least more than half of the children should be engaged in the process and tested for success.

\section{Use of Open Access Resources in ZSE RC [13]}

In developing countries getting an access to quality resources on the web is a major issue. But, if we get an access to quality resources, and that too free, the over all education scenario will get a face lift. Since teachers and librarians are the main providers of information resources, they can help the students to increase their achievement level. Open Access resources,

- help in making teaching, learning and research easier,

- help in developing a curriculum that will prepare students for the future,

- give the students more information to add on to the curriculum,

- help in identifying required \& quality information without wasting much time,

- help in achieving any librarian's universal mission of providing right information to the right person at the right time, in the right format, all this absolutely free, and

- help in identifying the relevant policies and practices of library professionals in the developed countries at the school level

To drive home these points, an attempt was made to create awareness among teachers about the freely available quality educational resources available on web and the benefits that they can gain by using them.

The objectives of implementing this practice were

- To make an effort to locate, identify, evaluate, organize and provide access to useful, reliable and quality websites for benefits of teachers and students

- Creating awareness among the teachers about the availability of free, quality, educational, electronic resources for teaching and learning. 
- To identify, understand and implement means \& ways to provide access to these free resources and encourage their usage.

- To explore the need for creating a portal of the selected quality, educational electronic resources to supplement the print collection.

An indicative list of forty five free quality educational electronic resources representing almost every discipline covered in the school curriculum with annotation was compiled specially and given to all teachers. A separate presentation was made to create awareness about web based resources/open access resources and accessibility and usefulness of the same. Some of the resources were covered as a part of the presentation, just to demonstrate the fact that how useful is the information covered in these sites and how well these sites are organized. Teachers were requested to visit each and every site (from the list given) in their subject area and were requested to find out the usefulness of the same for teaching purpose.

The success indicators of this practice were

- The accessibility to these free resources has bought in a global perspective to the concept of teaching and learning in school education, as the teachers, students and librarians have access to research work of the experts/professionals in their field of interest from the developed world.

- Teachers showed keen interest in understanding technology and also realized that using Internet/WWW is easier as well as beneficial.

- Due to the awareness about the free quality electronic resources, there is an increased demand from the teachers to assist them in identifying many more quality web resources in their respective teaching fields.

- A need for creating a portal listing all major resources has been clearly expressed by teachers.

- Teachers are now willing to look beyond textbooks or prescribed books and reference books for add on value to their teaching.

- They have become more vocal in their demand for Internet connectivity in the Resource Centre on more systems.

- Teachers visit the Resource Centre more often now to access many of the listed electronic resources.

Access to the Internet at the $\mathrm{RC}$ is a prerequisite. List of Open Access Resources relevant to the school environment compiled and updated regularly is an essential requirement. Necessary hardware/software installed at the user terminals is equally important. Dedicated teachers and well informed and genuinely interested management is a bonus to the success of this service.

Most of the above mentioned practices are experimented in a single library. If they have to gain credibility, they have to be tried in many other schools with some addition or improvement or local variation and then success rate can be measured. 


\section{Future Plans}

Zydus School for Excellence Resource Centre aims at being a role model for school library as foundation for world class learning. In order to fulfill its aim, some plans for the future are mentioned as below

- To create a Learning Resource Centre, wherein major electronic resources will be added to the existing print resources to facilitate students' learning and teachers' teaching process

- To create a portal to serve as an Information Gateway wherein students can access the resources from home to do their assignments, projects, etc.

- The Resource Centre will be the place wherein the students' achievement will be in focus by providing facilities and services to enable learning, discussions and reflections

- The Resource Centre will be the hub for the school's, teachers' and students' scholarly work in the form of Institution Repository.

- The Resource Centre will create space for an Incubation Centre for nurturing students' ideas, dreams and goals, providing them guidance, facilities and resources

\section{Conclusion}

The effort to compile such innovative practices was altogether a great learning experience which leads to some suggestions listed below.

- The annual conferences conducted by IFLA, IASL, ALA, SLA, etc. can take up the task of undertaking further research on best practices in school libraries for world class learning.

- Working groups can also be formed to prepare strategies for evaluating and implementing such best practices.

- Links can be created between libraries who have implemented the best practices with the libraries that have the potential to implement.

- Also opportunities can be provided for training programmes and workshops during the period of the conferences.

These practices discussed in this paper are simple, innovative and create a positive impact on the student. They also increase the library's contribution in achieving the school mission as well as aim at becoming the foundation for world class learning. There is always scope for refining and improving the strategies tried and tested, in the course of time to suite the ever changing landscape of information and technology and more importantly, to satisfy the ever demanding user and his needs. What one needs is deep commitment to the idea of developing new understanding, in depth knowledge and wisdom about learning in the world. The bottom line is to develop a driving passion for highest possible standards of learning. 


\section{References}

1. Houston, Cynthia (2006) "Building Capacity for Global Education in a School Library Media Education Program through International Exchange", Available at:

http://www.ifla.org/V/iflaj//FLA-Journal-4-2006.pdf

2. Smith, Kathleen (2002) "Building Student Learning through School Libraries", Available at: http://www.imls.gov/pubs/whitehouse0602/kathleensmith.htm

3. Kumbar, Rashmi "Application of Howard Gardner's Multiple Intelligence Theory for the Effective Use of Library Resources by K-2 Students: An Experimental Model": 72 ${ }^{\text {nd }}$ IFLA General Conference and Council - School Libraries \& Resource Centers section, Seoul, August 2006

4. Libraries - Gateways to Knowledge: A Roadmap for Revitalization. Available at: http://knowledgecommission.gov.in/focus/libraries.asp

5. Libraries - Gateways to Knowledge: A Roadmap for Revitalization. Available at:

http://knowledgecommission.gov.in/focus/schools.asp

6. Andhra Matha, K (2002) "School Libraries - Problems and Prospects: Some Observations", Seminar paper on Changing Times and Challenging Role of School Libraries, p.32

7. Libraries - Gateways to Knowledge: A Roadmap for Revitalization. Available at: http://knowledgecommission.gov.in/focus/libraries.asp

8. Venkanna, P (2002) "Present Status of School Libraries, East Godavari Dist., Andhra Pradesh", Seminar paper on Changing Times and Challenging Role of School Libraries, p.37

9. Bell, Steven ( Jan/Feb 2008) "Design thinking”, American Libraries, p.44-49

10. Kumbar, Rashmi (2007) "Paradigm Change In School Librarianship: Best Practices In Zydus School Resource Center" In Library and Information Science Profession in the Knowledge Society (Prof. C R Karisiddappa Festschrift), p142.

11. Jackson, Young and Bell, Helen (2008) "Learning side by side", American Libraries, p. 68-69

12. Kumbar, Rashmi “Application of Howard Gardner's Multiple Intelligence Theory for the Effective Use of Library Resources by K-2 Students: An Experimental Model": $72^{\text {nd }}$ IFLA General Conference and Council - School Libraries \& Resource Centers section, Seoul, August 2006

13. Kumbar, Rashmi "Effective Use of Open Access Resources in a School Library: A Case Study of Zydus School for Excellence Resource Centre": $36^{\text {th }}$ Annual IASL Conference held at Taipei, July 2007 


\begin{abstract}
Author Profile
Ms. Rashmi Kumbar holds Masters Degree in Library and Information Science (with Gold Medal) and Masters Degree in Arts, from Gujarat University and Karnatak University respectively. She has also done her Post Graduate Diploma in Library Automation and Networking from University of Hyderabad. She is currently working for Zydus School for Excellence as the Librarian and is with the school for the last six years. She is passionate about school libraries and its role in developing over all personality of students and has won 'Lead Learner Award 2004' in her school for her contributions to the school. Her paper titled 'Application of Howard Gardner's Multiple Intelligence Theory for the Effective Use of Library Resources by K-2 Students: An Experimented Model' was presented at the $72^{\text {nd }}$ IFLA General Conference and Council in the School Libraries and Resource Centers section in Seoul in August 2006. Another paper titled "Effective Use of Open Access Resources in a School Library: A Case Study of Zydus School for Excellence Resource Centre" was presented at the $36^{\text {th }}$ Annual IASL Conference in Taipei in July 2007.
\end{abstract}

\title{
Statement of Originality
}

This statement certifies that the paper above is based upon original research undertaken by the author and that the paper was conceived and written by the author alone and has not been published elsewhere. All information and ideas from others is referenced. 